\title{
LOS DERECHOS HUMANOS DENTRO DE LA NUEVA FISCALIZACIÓN
}

\section{HUMAN RIGHTS WITHIN THE NEW AUDIT}

\author{
Dr. Gerardo Hernández Barrena ${ }^{\text {a }}$ \\ Lic. Judith Andrea Hernández Ortega ${ }^{\text {b }}$ \\ Dr. Sergio Gabriel Ordoñez Sánchez ${ }^{c}$ \\ Lic. Wendolyne Sosa Robles ${ }^{d}$
}

\author{
${ }^{a}$ Benemérita Universidad Autónoma de Puebla \\ Facultad de Contaduría Pública, barrenagerardo@yahoo.com.mx \\ ${ }^{\mathrm{b}}$ Benemérita Universidad Autónoma de Puebla \\ Facultad de Contaduría Pública, judi_andy@ hotmail.com \\ ${ }^{\mathrm{c}}$ Benemérita Universidad Autónoma de Puebla \\ Facultad de Contaduría Pública, sergio.buap@gmail.com \\ ${ }^{\mathrm{d}}$ Universidad Autónoma de Tlaxcala \\ roblesw53@gmail.com
}

Fecha de recepción: 31 de enero de 2020

Fecha de aceptación: 25 de marzo de 2020

\section{RESUMEN}

En la actualidad las autoridades fiscales vigilan el correcto cumplimiento de las obligaciones fiscales de los contribuyentes mediante la revisión de los comprobantes fiscales digitales, sin embargo, ante cualquier irregularidad en su emisión o ante la omisión en su expedición, dichas autoridades no consideran la deducción o el acreditamiento al contribuyente que adquiere los bienes o servicios lo que podría configurar transgresión a sus Derechos Humanos, es por ello que se realizó la presente investigación de tipo exploratoria, por los datos empleados de tipo cualitativa, con un método de investigación deductivo y tipo de estudio documental, concluyendo en que las autoridades fiscales no están interpretando las leyes fiscales de manera que favorezcan al contribuyente, quebrantando la Constitución Política de los Estados Unidos Mexicanos.

PALABRAS CLAVE: Comprobantes fiscales digitales por internet; Derechos Humanos; Contribuyentes. 


\section{ABSTRACT}

At present the tax authorities monitor the correct compliance with taxpayers' tax obligations by reviewing digital tax receipts, however, in the face of any irregularities in their issuance or omission in their issuance, those authorities do not consider deduction or accreditation to the taxpayer purchasing the goods or services which could set up transgression to their Human Rights, that is why the present exploratory investigation was carried out, by the data used of a qualitative type, with a method of deductive research and type of documentary study, concluding that the tax authorities are not interpreting the tax laws in a way that favors the taxpayer, breaking the Political Constitution of the United Mexican States.

KEYWORDS: Online Digital Tax Proof; Human Rights; Taxpayers.

\section{INTRODUCCIÓN}

En la actualidad la protección de los derechos humanos juega un papel fundamental en la vida de las personas, en donde cada vez se exige al Estado la defensa más amplia y el ámbito tributario no debe ser la excepción, en ese sentido las autoridades fiscales deben proteger, garantizar, promover y respetar los Derechos humanos de los contribuyentes, lo cual debe abarca el aspecto contributivo así como aquellas obligaciones secundarias que coadyuvan con el contribuyente para que cumpla su obligación de pagar sus impuestos, tales como: llevar contabilidad, presentar declaraciones y avisos, emitir comprobantes fiscales digitales por internet, etc. En ese contexto las autoridades fiscales tienen la facultad de vigilar el correcto cumplimiento de las disposiciones fiscales de los contribuyentes mediante actos de fiscalización, sin embargo en la actualidad dicha fiscalización se realiza de una manera más ágil ya que al emitirse la facturación de los contribuyentes mediante herramientas electrónicas, permite a la autoridad cerciorarse de unos de los requisitos primordiales para la deducción y acreditamiento en los impuestos sobre la renta y al valor agregado respectivamente.

Dentro del ámbito contributivo, las obligaciones que cumplir como lo son el pago de impuestos, envío de contabilidad, retener, presentar declaraciones etcétera, sin embargo, por otro lado los derechos que la autoridad tiene la obligación de proteger en todo momento a 
través de la interpretación de las leyes, dentro de estos derechos encontramos la facilidad de disminuir la carga tributaria a través de erogaciones, sin embargo estas erogaciones se encuentran sujetas a requisitos que deben ser cumplidos de manera estricta y uno de ellos siendo de los más importantes es estar amparado con un Comprobante Fiscal Digital por Internet, que para los adquirentes del producto o servicio es indispensable solicitarlo ante el proveedor así como cumplir con los requisitos de tiempo y forma de pago sin embargo no todos los proveedores efectúan dicha acción y por ende el contribuyente se ve afectado al no poder realizar la acreditación y deducibilidad ya que las autoridades fiscales dentro de sus facultades de comprobación no consideran deducible un acto que no se encuentra amparado con un CFDI y dando paso a violentar los derechos de los contribuyentes ya que de alguna manera la sanción recae sobre la adquiriente y no sobre el proveedor donde en ningún momento se interpreta la ley favoreciendo al contribuyente.

La comunidad internacional en el año de 1948 se vio en la necesidad de instaurar dentro de un documento instrumentos para el desarrollo armónico de las personas, fue entonces que se creo la Declaración Universal de los Derechos Humanos estableciendo 30 artículos que ayudan a proteger el bienestar de cada individuo abarcando aspectos sociales, políticos, económicos, medio ambientalistas, etc.

En México, dentro de la normatividad internacional y de los tratados de los que forma parte adoptó esta declaración a través de nuestra carta magna para coadyuvar la protección de los derechos humanos, el pasado 10 de junio de 2010, la Constitución Política de los Estados Unidos Mexicanos a través de una reforma en materia de derechos humanos, dejó atrás el concepto de garantías individuales para poder dar paso a los derechos humanos y sus garantías donde fueron reformados 11 artículos, de los cuales el artículo $1^{\circ}$ resalta la interpretación de las leyes que favorezcan a los individuos.

Dentro de este orden de ideas, la protección del aspecto contributivo derivado del ámbito económico debe ser protegido sin distinción alguna, donde de acuerdo con la constitución se deben interpretar las leyes fiscales de manera que los contribuyentes puedan cumplir con sus obligaciones considerando la posición en la que se encuentran. En este sentido las autoridades deben considerar la deducibilidad de un acto realizado por el contribuyente para 
poder ser disminuido de su carga tributaria cuando después de cumplir los requisitos el proveedor no le proporcione su comprobante para poder integrarla erogación realizada de un producto o servicio.

El objetivo de esta investigación es dilucidar si dentro de las actuaciones de las autoridades fiscales que efectúan sus facultades de comprobación, protegen los derechos humanos al interpretar las leyes fiscales favoreciendo a los contribuyentes dentro del esquema de Comprobantes Fiscales Digitales por Internet para hacer deducible o acreditable las erogaciones y poder ser disminuidas de los ingresos, aun cuando no se tenga un CFDI que lo avale derivado de la falta de suministro por el proveedor pero se hayan cumplido las demás obligaciones que tiene el adquiriente.

\section{LOS DERECHOS HUMANOS Y EL ÁMBITO FISCAL}

Los derechos humanos surgen a través del tiempo tras la necesidad de proteger y hacer valer la dignidad humana de las personas sin importar su raza, color, religión, idioma, condición económica, física o de cualquier otra índole. Estos derechos se encuentran reconocidos en la Declaración Universal de los Derechos Humanos de 1948 la cual fue proclamada por la Asamblea General de las Naciones Unidas después de actos barbaros llenos de violencia, guerra, asesinato y por su puesto la agresión en contra de la vida de las personas.

Entonces, los derechos humanos son aquellas normas que protegen el bienestar de cada persona donde el objetivo primordial es la convivencia armónica entre individuos asegurando la paz, seguridad y un orden social para el bienestar mutuo.

Desde el punto de vista dualista se observan a los derechos humanos como provenientes de la naturaleza humana y que en conjunto con el sistema jurídico deben de ser protegidos el autor (Peces-Barba, 1979) considera que los derechos humanos son la facultad que la norma atribuye de protección a la persona en lo referente a su vida, su libertad, a la igualdad, a su participación política y social, o cualquier otro aspecto fundamental que afecte a su desarrollo integral como persona, en una comunidad de hombres libres, exigiendo respeto de los demás hombres, de los grupos sociales del estado, y con la posibilidad de pones en marcha el aparato coactivo del estado en caso de infracción. 
Dentro de este marco el Profesor Eusebio Fernández (1982) menciona que toda persona posee unos derechos morales por el hecho de serlo y estos deben ser reconocidos y garantizados por la sociedad, el derecho y el poder político, sin ningún tipo de discriminación social, económica, jurídica, política, ideológica, cultural o sexual. Estos derechos son fundamentales, es decir se hallan estrechamente conectados con la idea de la dignidad humana y son al mismo tiempo las condiciones del desarrollo de esa dignidad.

Sin embargo, Manuel Peris (1976) dice que el concepto y formulación de los derechos humanos se han ido decantando a través de la historia, a partir del núcleo teórico más amplio de humanidad, entendida esta no en su apoyo sentimental, si no como un proceso de autoconciencia, mediante el cual se ha objetivado la esencia del hombre como un concepto unitario y abstracto.

En la perspectiva de Norberto Bobbio (1966) señala que no se trata de encontrar la definición exacta de lo que son los derechos humanos o un fundamento absoluto, si no de encontrar diversas manifestaciones de su significado. Resalta que el estudio primordial para conocer lo que son es relacionar las condiciones de los medios y las situaciones de donde provinieron para establecerlos, ya que, no pueden estar disociados de los problemas sociales, políticos, económicos, psicológicos e históricos y que son inherentes a su ejecución.

Desde estas perspectivas y desde la proclamación de los derechos humanos en 1948 cada país ha ido incorporando en su legislación las leyes que garanticen, promuevan y protejan los derechos de cada persona. A través de la Organización de las Naciones Unidas se ha buscado el reconocimiento de los derechos de las personas siendo el órgano regulador a nivel mundial de los países adheridos a estas normas.

En México a través de la Constitución Política de los Estados Unidos Mexicanos se instauró en sus primeros 29 artículos la amplia protección de los derechos humanos estableciendo la igualdad en derechos y obligaciones que garanticen la convivencia, paz, armonía y vida digna de las personas. A través de una reforma el pasado 10 de junio de 2011 se da un paso trascendental en relación con los derechos humanos ya que se deja atrás el concepto de "garantías individuales" para aplicar "los derechos humanos y sus garantías". 
Este acontecimiento lleva a hacer mención del artículo $1^{\circ}$ (Constitución Política de los Estados Unidos Mexicanos, 1917) en su párrafo tercero donde indica que:

Todas las autoridades, en el ámbito de sus competencias, tienen la obligación de promover, respetar, proteger y garantizar los derechos humanos de conformidad con los principios de universalidad, interdependencia, indivisibilidad y progresividad. En consecuencia, el Estado deberá prevenir, investigar, sancionar y reparar las violaciones a los derechos humanos, en los términos que establezca la ley. (párr. 3)

En este orden de ideas y desde nuestra perspectiva el Estado no debe pasar por alto el ámbito económico, en especial el área fiscal por el cual el estado a través del pago de impuestos obtiene recursos para satisfacer las necesidades fundamentales de la sociedad, que a pesar de ser una obligación constitucional las autoridades deben corroborar que se esté llevando la recaudación conforme a la ley y que además se proteja en todo momento al contribuyente.

Debe señalarse entonces que una de las formas en que las autoridades buscan actualmente vigilar y tener un control tributario es a través de los Comprobantes Fiscales Digitales por Internet mejor conocidos como CFDI o Factura electrónica que Rodríguez (2015) define que es un documento en formato digital que sirve como comprobante fiscal con validez legal, que utiliza estándares técnicos de seguridad definidos por el Servicio de Administración Tributaria y por organizaciones reconocidas internacionalmente, mismas que permiten garantizar la integridad, confidencialidad, autenticidad y unicidad de la Factura.

Pérez (2016) manifiesta que la factura electrónica es, por tanto, la versión de las facturas tradicionales en papel y debe ser funcional y legalmente equivalente a estas últimas. Por su propia naturaleza, las facturas electrónicas pueden almacenarse, gestionarse e intercambiarse por medios electrónicos o digitales.

De acuerdo con el Diario Oficial de la Federación (2013), se estableció como único medio de comprobación válido al CFDI, en su segundo artículo transitorio que se refiere el Artículo Único de este Decreto, se estará a lo siguiente: 
IV. Cualquier referencia a comprobantes fiscales digitales por Internet, que se señalen en el Código Fiscal de la Federación se entenderán comprendidos a cualquier comprobante fiscal emitido conforme a la legislación vigente, respecto del ejercicio correspondiente a 2013 y anteriores. Asimismo, cualquier referencia a comprobantes fiscales en leyes, reglamentos y demás disposiciones aplicables, se entenderán hechos a los comprobantes fiscales digitales por Internet.

I. Cumplir con las especificaciones que en materia de informática determine el Servicio de Administración Tributaria mediante reglas de carácter general.

Anudado a lo expuesto anteriormente, los Comprobantes Digitales por Internet deberán contener los siguientes:

I. Contar con un certificado de firma electrónica avanzada vigente conocida como FIEL.

II. El número de folio y el sello digital del Servicio de Administración Tributaria

III. El lugar y fecha de expedición.

IV. La clave del registro federal de contribuyentes de la persona a favor de quien se expida.

V. La cantidad, unidad de medida y clase de los bienes o mercancías o descripción del servicio o del uso o goce que amparen.

VI. El valor unitario consignado en número.

VII. El importe total consignado en número o letra

VIII. Tratándose de mercancías de importación:

a) El número y fecha del documento aduanero, tratándose de ventas de primera mano.

b) En importaciones efectuadas a favor de un tercero, el número y fecha del 
documento aduanero, los conceptos y montos pagados por el contribuyente directamente al proveedor extranjero y los importes de las contribuciones pagadas con motivo de la importación.

IX. Los contenidos en las disposiciones fiscales, que sean requeridos y dé a conocer el Servicio de Administración Tributaria, mediante reglas de carácter general.

En este sentido se comprende que en México se han tomado medidas trascendentales a través de los años para facilitar la recopilación e intercambio de información de adquiriente a proveedor y viceversa, además de disminuir la posibilidad de una falsificación de información que a su vez protege la integridad del contribuyente, así como de la autoridad que lo revela.

Para el cumplimiento de las obligaciones fiscales, las leyes establecen independientemente de nuestra obligación de contribuir, otras obligaciones que coadyuvan a la obligación de pago de los impuestos; en ese sentido, se deben presentar declaraciones y avisos, enviar contabilidad, etc., siendo un deber relevante para los contribuyentes la de emitir y solicitar los comprobantes fiscales digitales, para con ello dar cabal cumplimiento al artículo 29 del Código Fiscal de la Federación (2020):

"Cuando las leyes fiscales establezcan la obligación de expedir comprobantes fiscales por los actos o actividades que realicen, por los ingresos que se perciban o por las retenciones de contribuciones que efectúen, los contribuyentes deberán emitirlos mediante documentos digitales a través de la página de Internet del Servicio de Administración Tributaria. Las personas que adquieran bienes, disfruten de su uso o goce temporal, reciban servicios o aquéllas a las que les hubieren retenido contribuciones deberán solicitar el comprobante fiscal digital por Internet respectivo.

Con ello el contribuyente adquirente en términos de la Ley del Impuesto sobre la Renta puede disminuir de los ingresos obtenidos, las erogaciones realizadas, siempre que cumplan con el requisito de solicitar el comprobante respectivo, para con ello dar cumplimiento a uno de los tantos requerimientos que se contemplan en el artículo 27 de la Ley del Impuesto sobre la Renta (2020), en ese sentido dicha disposición señala: 
"Las deducciones autorizadas en este Título deberán reunir los siguientes requisitos:

III. Estar amparadas con un comprobante fiscal..."

En ese contexto y para efectos de la Ley del Impuesto al Valor agregado (2020), los contribuyentes pueden disminuir del impuesto causado, el impuesto pagado por la adquisición de bienes o la prestación de servicios, siempre que cumplan con el artículo 5 fracción segunda:

"Para que sea acreditable el impuesto al valor agregado deberán reunirse los siguientes requisitos:

II. Que el impuesto al valor agregado haya sido trasladado expresamente al contribuyente y que conste por separado en los comprobantes fiscales..."

Es así como el contribuyente que adquiera bienes y servicios podrá disminuir de su impuesto causado el impuesto pagado por la adquisición de bienes o prestación de servicios siempre que dicho impuesto se encuentre expreso y por separado en un comprobante fiscal.

En ese contexto cuando las autoridades fiscales ejercen sus facultades de comprobación en términos del artículo 42 del Código Fiscal de la Federación (2020) contempla nueve actos que pueden practicar dichas autoridades para vigilar el correcto cumplimiento de las obligaciones fiscales de los contribuyentes y con ello comprobar que tanto las erogaciones realizadas por el contribuyente así como el impuesto al valor agregado pagado por las mismas, cumplen con los requisitos para ser deducibles y acreditables.

En ese sentido y en términos del artículo $1^{\circ}$ de la Constitución Política de los Estados Unidos Mexicanos el Estado tiene la obligación de promover, proteger, garantizar y respetar los derechos humanos de las personas, interpretando las leyes de manera que favorezcan a los contribuyentes.

En relación con la problemática expuesta se realizó una entrevista a las autoridades fiscales del Estado de Puebla, específicamente en el área de auditoria para conocer su opinión acerca de los Comprobantes Fiscales Digitales por Internet, donde se obtuvieron los siguientes resultados (Figura 1): 


\section{Figura 1}

Comprobantes Fiscales

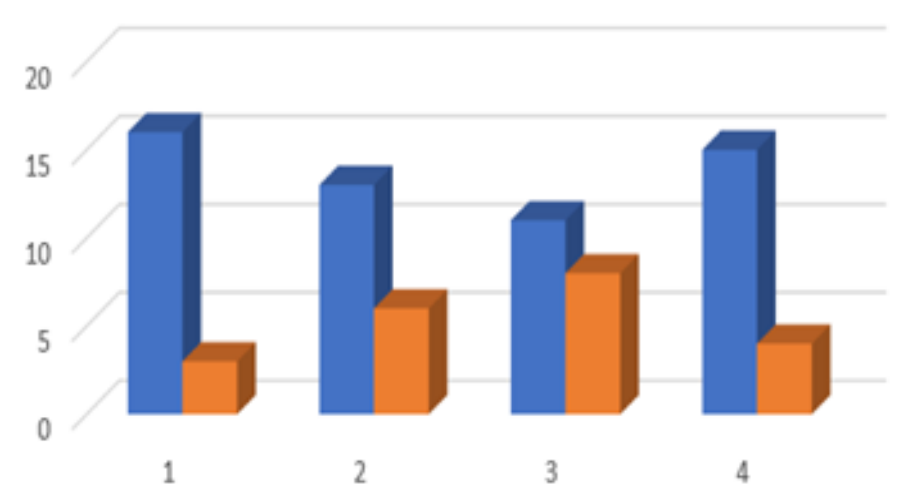

Fuente Elaboración Propia (2019).

El color azul muestra:

1. Veces que la autoridad no considera deducible ni acreditable un acto por no estar amparado con un CFDI.

2. A juicio del auditor, es necesario el amparo con un CFDI.

3. De manera particular, consideran que todas las operaciones deben contener un CFDI.

4. A juicio de la autoridad, se trasgreden los Derechos Humanos de los contribuyentes.

Se resume entonces que las autoridades fiscales consideran necesario que todo acto realizado por el contribuyente para poder ser considerado deducible o acreditable debe está amparado por un CFDI; reconoce que se transgreden los derechos humanos de los mismos cuando al adquirir un bien o servicio, la propia autoridad no le permite la deducción acreditamiento para efectos de los impuestos sobre la renta y al valor agregado.

Dentro de este orden de ideas se expone la situación que aqueja a los contribuyentes, ya que, queda a la deriva, en una posicion de indefensión puesto que dependemos de la opinión o interpretación de la persona o la autoridad que nos está efectuando la revisión de nuestras operaciones, no existe un parámetro especifico que otorgue uniformidad a la aplicación de las leyes. 


\section{METODOLOGÍA, TÉCNICAS Y MATERIALES EMPLEADOS}

El enfoque de esta investigación ha sido cualitativo ya que se realizó una recopilación de información acerca del tema presentado para poder definir una opinión concisa.

Se utilizo el método de investigación deductivo para poder realizar una conclusión lógica en base a los datos recabados acerca de los derechos humanos y los métodos de interpretación de las leyes, así mismo se utilizó un tipo de estudio documental ya que se realizó la consulta en leyes, normas vigentes, decretos, revistas, libros etc., todo con la finalidad de dilucidar si las autoridades fiscales promueven, protegen, respetan y garantizan la protección de los derechos humanos bajo el esquema de sus facultades de comprobación establecidas en estos documentos.

\section{RESULTADOS Y DISCUSIÓN}

Para el cumplimiento de obligaciones fiscales, las leyes establecen independientemente de nuestra obligación de contribuir, otras obligaciones que coadyuvan a la obligación de pago de los impuestos; en ese sentido, se debe de presentar declaraciones y avisos, enviar contabilidad, etc., siendo un deber relevante para los contribuyentes la de emitir y solicitar los comprobantes fiscales digitales, para con ello dar cabal cumplimiento al artículo 29 del Código Fiscal de la Federación (2020):

"Cuando las leyes fiscales establezcan la obligación de expedir comprobantes fiscales por los actos o actividades que realicen, por los ingresos que se perciban o por las retenciones de contribuciones que efectúen, los contribuyentes deberán emitirlos mediante documentos digitales a través de la página de Internet del Servicio de Administración Tributaria. Las personas que adquieran bienes disfruten de su uso o goce temporal, reciban servicios o aquéllas a las que les hubieren retenido contribuciones deberán solicitar el comprobante fiscal digital por Internet respectivo".

Con ello el contribuyente adquirente en términos de la Ley del Impuesto sobre la Renta puede disminuir de los ingresos obtenidos, las erogaciones realizadas, siempre que cumplan con el requisito de solicitar el comprobante respectivo, para con ello dar cumplimiento a uno de los tantos requerimientos que se contemplan en el artículo 27 de la Ley del Impuesto 
sobre la Renta (2020), en ese sentido dicha disposición señala:

"Las deducciones autorizadas en este Título deberán reunir los siguientes requisitos:

III. Estar amparadas con un comprobante fiscal..."

En ese contexto y para efectos de la Ley del Impuesto al Valor agregado (2020), los contribuyentes pueden disminuir del impuesto causado, el impuesto pagado por la adquisición de bienes o la prestación de servicios, siempre que cumplan con el artículo 5 fracción segunda:

"Para que sea acreditable el impuesto al valor agregado deberán reunirse los siguientes requisitos:

II. Que el impuesto al valor agregado haya sido trasladado expresamente al contribuyente y que conste por separado en los comprobantes fiscales..."

Es así como el contribuyente que adquiera bienes y servicios podrá disminuir de su impuesto causado el impuesto pagado por la adquisición de bienes o prestación de servicios siempre que dicho impuesto se encuentre expreso y por separado en un comprobante fiscal.

En ese contexto cuando las autoridades fiscales ejercen sus facultades de comprobación en términos del artículo 42 del Código Fiscal de la Federación (2020) contempla nueve actos que pueden practicar dichas autoridades para vigilar el correcto cumplimiento de las obligaciones fiscales de los contribuyentes y con ello comprobar que tanto las erogaciones realizadas por el contribuyente así como el impuesto al valor agregado pagado por las mismas, cumplen con los requisitos para ser deducibles y acreditables.

En ese sentido y en términos del artículo $1^{\circ}$ de la Constitución Política de los Estados Unidos Mexicanos el Estado tiene la obligación de promover, proteger, garantizar y respetar los derechos humanos de las personas, interpretando las leyes de manera que favorezcan a los contribuyentes. 


\section{CONCLUSIONES}

El Estado debe promover, proteger y garantizar los derechos humanos de los contribuyentes en apego al artículo $1^{\circ}$ de la Constitución Política de los Estados Unidos Mexicanos, respetando en todo momento la interpretación de las leyes a favor de las personas.

El ámbito económico de las personas también se encuentra protegido por los derechos Humanos y por ende el aspecto contributivo, por lo que las leyes fiscales también debieran interpretarse de manera que protejan los Derechos Humanos de los contribuyentes.

Por otro lado, los contribuyentes tienen la obligación de emitir comprobantes fiscales digitales por los ingresos que perciben, de no hacerlo, las autoridades fiscales consideran que su cliente no puede hacer deducible ni acreditable, las adquisición de bienes o la prestación de servicios para efectos de los impuestos sobre la renta y al valor agregado respectivamente, siendo que dicho cliente cumplió con su obligación de solicitar el comprobante respectivo, viéndose imposibilitado de cumplir con el artículo 27 fracción III de la ley del impuesto sobre la Renta así como el artículo 5 fracción II de la ley del impuesto al valor agregado, por lo que una interpretación favorable al contribuyente por parte de las autoridades fiscales, se le debiera permitir deducir y acreditar y no ser transgredido en sus derechos por la acción de un tercero, en este caso su proveedor.

Es importante señalar que las autoridades fiscales dentro de su página electrónica permiten la denuncia por no emitir comprobantes fiscales, dando seguimiento a través de buzón tributario, sin embargo, no hay algún pronunciamiento por parte de dichas autoridades para los casos en que se emita el comprobante fuera de los plazos establecidos por las leyes fiscales, lo que sin duda daría el mismo resultado de ser la operación no deducible ni acreditable. 


\section{REFERENCIAS}

Bobbio, N. (1966). Lilusiòn du foundement absolu . La Nuova Italia, Firenze : Institut International de Philosophie.

Código Fiscal de la Federación. (2020).

Constitución Política de los Estados Unidos Mexicanos. (1917).

$\begin{array}{llllll}\text { Diario } & \text { Oficial de } & \text { Federeacion } & \text { (2013). }\end{array}$ http://dof.gob.mx/nota_detalle.php?codigo=5324942\&fecha=09/12/2013.

Fernández, E. (1982). El Problema del Fundamento de los Derechis Humanos . Madrid: Editorial Universidad Complutanse de Madrid .

Lauro E. Arias Blanco. (2019). Instituo Mexicano de Contadores Publicos . Obtenido de https://imcp.org.mx/areas-de-conocimiento/fiscal/la-historia-de-la-factura-electronica-en-mexicotiene-ya-mucho-tiempo-derivado-del-esfuerzo-de-personas-y-organismos-que-deseaban-suaplicacion-en-nuestro-pais/

Ley del Impuesto al valor agregado. (2020).

Ley del Impuesto sobre la Renta. (2020).

Peces-Barba, G. (1979). Derechos Fundamentales. Madrid: Edutorial Latina Universitaria.

Pèrez, S., Garza , C., \& Soto , M. (6 de Febrero de 2016). Vital Sistemas. Obtenido de Definición de términos utilizados en la Facturación Electrónica: http://blog.vital.com.mx/?p=72

Peris, M. (1976). JUEZ, ESTADO Y DERECHOS HUMANOS . Valencia España: Editorial Fernando Torres .

Rigoberto Flores . (3 de Junio de 2013). FACTURA-T. Obtenido de http://www.facturat.com/facturacionelectronica-2014/

Rodrìguez, I. H. (12 de Noviembre de 2015). VILLANET. Obtenido de FACTURA ELECTRÓNICA EN MÉXICO Y SU MARCO JURÍDICO: http://www.nube.villanett.com/2015/11/12/facturaelectronica-en-mexico/ 